ISSN: 2215-2644

revedu@gmail.com

Universidad de Costa Rica

Costa Rica

\title{
Cómo luchar contra microorganismos resistentes a medicamentos Difusión de conocimientos científicos en una escuela secundaria
}

Pérez, Cristina; Farah, Ezequiel; Rulli, Florencia

Cómo luchar contra microorganismos resistentes a medicamentos Difusión de conocimientos científicos en una escuela secundaria

Revista Educación, vol. 42, núm. 2, 2018

Universidad de Costa Rica, Costa Rica

Disponible en: http://www.redalyc.org/articulo. $0 a$ ? id=44055139010

DOI: https://doi.org/10.15517/revedu.v42i2.24246

Esta obra está bajo una Licencia Creative Commons Atribución-NoComercial-SinDerivar 3.0 Internacional. 


\title{
Cómo luchar contra microorganismos resistentes a medicamentos Difusión de conocimientos científicos en una escuela secundaria
}

\author{
How to fight against microorganisms resistant to medications: Diffusion of scientific knowledge in a secondary \\ school
}

Cristina Pérez [1]

Universidad de Buenos Aires, Argentina

Cristina.perez@odontologia.uba.ar

Ezequiel Farah [2]

Universidad de Buenos Aires, Argentina

Ezequiel_dario@hotmail.com

Florencia Rulli [3]

Ministerio de Educación, Argentina

florenciarulli@hotmail.com
DOI: https://doi.org/10.15517/revedu.v42i2.24246 Redalyc: http://www.redalyc.org/articulo.oa?id=44055139010

\section{Resumen:}

En este artículo se da cuenta de una actividad docente que incluye difusión científica en una escuela secundaria municipal de la ciudad de Buenos Aires (Argentina). En ella se relacionaron las áreas de biología y química con el alumnado de primero, segundo y cuarto años. Se realizó un repaso e integración de algunos conocimientos seleccionados; luego se agregaron contenidos de las disciplinas universitarias farmacología y microbiología, así como datos científicos generados por nuestro equipo de investigación de la Universidad de Buenos Aires y el Consejo Nacional de Investigaciones Científicas y Técnicas (CONICET). Se diseñaron clases teóricas y trabajos prácticos interactivos adecuados a los temas tratados y al laboratorio escolar. El tema central incluyó infecciones comunes en adolescentes como las producidas por hongos. Considerados stos, se derivó luego a Candida albicans, su importancia clínica, diagnóstico, observación por microscopía óptica, tratamiento, etc. Se informó acerca del problema de la resistencia de microorganismos a medicamentos, sus mecanismos, su relevancia terapéutica y la necesidad de investigar sobre estrategias para luchar contra ella. A continuación, se dieron ejemplos de avances científicos recientes relacionados con la reversión de la resistencia de Candida albicans a medicamentos de tipo azol, producida por una sustancia abreviada como 6PP y extraída de la leguminosa Dalea elegans en Argentina. Se enriqueció el currículo escolar, con novedosa apertura a la ciencia real relacionada con la medicina y la bioquímica. Se promovió el cuidado de la salud en la comunidad educativa.

Palabras clave: Comunicación de la ciencia en escuelas, innovación pedagógica.

\section{ABSTRACT:}

In this paper, a teaching activity involving science communication in an official high school of Buenos Aires, Argentina is presented. Together with students from first, second and fourth school years, biology and chemistry topics were integrated. A selection, review

\section{NotAS DE AUTOR}

[1] Bioquímica, Licenciada en Química Farmacéutica y Doctora en Ciencias Químicas. Se graduó con honores en todos los niveles educativos. Su actuación profesional ha concernido fundamentalmente a la docencia, investigación científica y extensión universitarias. Actualmente es profesora adjunta de Farmacología e investigadora en la Universidad de Buenos Aires (Argentina). Ha publicado 71 artículos científicos, pedagógicos y periodísticos. Es una de las creadoras de la serie pedagógica "De la universidad a la escuela".

[2] Licenciado en Producción de Bioimágenes (Facultad de Medicina, Universidad de Buenos Aires). Es profesor en docencia superior (Universidad Tecnológica Nacional) y docente de Farmacología en la carrera de Licenciatura en Producción de Bioimágenes. Es profesor de educación media en las asignaturas biología y química en escuelas del Ministerio de Educación de la ciudad de Buenos Aires.

[3] Licenciada en Psicopedagogía, profesora de enseñanza primaria y preescolar. Ha ejercido la docencia en estos niveles y en secundario. Ha sido directora de enseñanza primaria, coordinadora psicopedagógica en jardines de infantes y directora de escuelas secundarias. Se ha desempeñado en áreas clínicas y pedagógicas del Ministerio de Educación del Gobierno de la Ciudad de Buenos Aires. Es una de las creadoras de la serie pedagógica "De la universidad a la escuela". 
and integration of knowledge were made. Contents of pharmacology and microbiology, along with scientific data, generated by some specialists at the University of Buenos Aires and the National Council of Scientific and Technical Research (CONICET in Spanish) were added. Interactive theoretical and practical classes were outlined adapted to the school laboratory and the classrooms. The main topic included common infections in teenagers, such as those produced by fungi. The topic was then oriented towards Candida albicans, its clinical relevance, diagnostic, observation thought optic microscopy, treatment, among others. The emergence of microorganisms resistant to antimicrobials was studied in relation to their mechanisms, therapeutic relevance and the need to do research on strategies to fight against them. In addition, some examples of recent scientific findings related to the reversion resistance of Candida albicans to azole-type medications were given. This resistance is produced by a flavonoid substance abbreviated as 6PP and extracted from the plant Dalea elegans which grows inArgentina. The school curriculum was improved with an innovative approach involving real science related to medicine and biochemistry. Health care was promoted in the school community..

KEYWORDS: science communication in schools, pedagogical innovation.

\section{FUNDAMENTACión Y ANTECEDENTES}

La sociedad actual ha incorporado a su vida cotidiana numerosos avances científicos que han generado grandes cambios en nuestra vida cotidiana, como la preservación de la salud, la forma de relacionarnos y de trabajar.

De acuerdo con declaraciones conceptuales de la UNESCO (1999; 2017), el futuro de la humanidad dependerá de la producción, difusión y utilización equitativas del saber. Las universidades que según sus funciones son generadoras de conocimientos científicos y tecnológicos, deben contribuir a acercar estos a los distintos sectores de las sociedades (Rietti, 1999). En este contexto, algunas universidades como la de Buenos Aires, por ejemplo, viene promoviendo distintas actividades de difusión y formación científica, enmarcadas como extensión universitaria, según plantean sus reglamentos. Entre ellas, se pueden citar muestras de ciencias y pasantías en distintas facultades, además de publicaciones como la revistas Exactamente, Nautilus, Química viva y Ciencia Hoy (Pérez, Rodríguez y Rulli, 2009).

La comunicación de la ciencia reviste gran importancia en las distintas instancias educativas (Díaz y Jiménez, 2012; Giordan y Sanmartino 2004) y debería implementarse desde los niveles iniciales, ya que los niños y las niñas tienen mayor potencialidad de incorporar la ciencia como valor cultural (Jaim Etcheverry, 2001). En este sentido, desde 2001 se está desarrollando la serie "De la universidad a la escuela", que comprende actividades docentes innovadoras para la enseñanza de las ciencias naturales con experimentación en escuelas de la ciudad de Buenos Aires y publicación en distintas revistas de educación (Pérez et al., 2003; 2005;-2013). En función de lo expuesto y considerando que la educación científica tiene particular relevancia en el desarrollo de las sociedades, este trabajo tuvo como objetivo general acercar la ciencia a la escuela secundaria, que maneja conocimientos más parecidos a los del nivel universitario y además capacita para la actividad laboral.

En este informe se da cuenta de la expansión de actividades innovadoras al nivel secundario a través de la organización de un taller de ciencias en una escuela municipal de la ciudad de Buenos Aires (Argentina). El tema central incluyó infecciones comunes en adolescentes como las producidas por hongos, y se derivó en particular a la especie Candida albicans. Se divulgaron trabajos científicos locales y los conocimientos universitarios necesarios para su comprensión.

\section{Información científica a difundir}

Ante la agresión de microorganismos patógenos, algunas plantas se defienden mediante toxinas antimicrobianas. Los invasores reaccionan desarrollando resistencia a éstas tas por diferentes mecanismos, uno de los cuales consiste en expulsarlas de sus células mediante proteínas transportadoras presentes en ellas. 
Así, estas bombas expulsoras disminuyen el contenido celular de los compuestos y les restan probabilidad de ejercer sus efectos.

Continuando el combate biológico, las plantas producen compuestos que inhiben las bombas, con lo cual aumenta el contenido de toxinas dentro de las células, se recupera su efecto antimicrobiano y se revierte la resistencia del microorganismo (Figura 1).
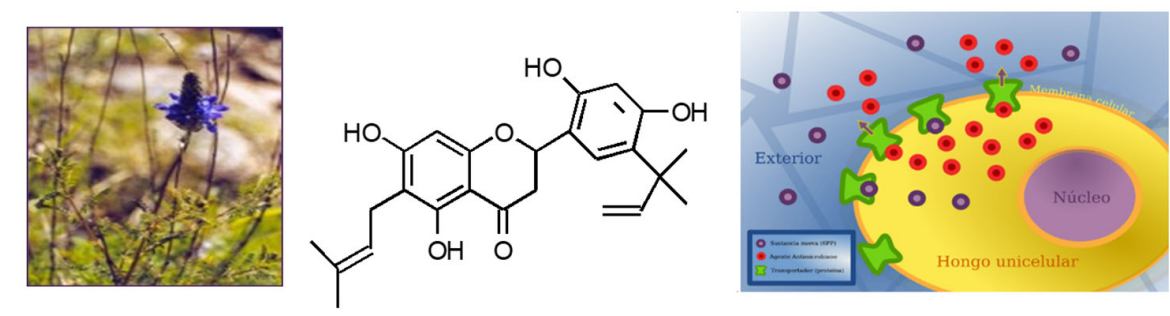

\section{FIGURA 1}

Dalea elegans (izquierda), planta productora del compuesto2',4'-dihidroxi-5'-(1"',1"'-dimetilalil)-6prenilpinocembrina (6PP; fórmula química en el centro), que inhibe bombas expulsoras de azoles presentes en algunos hongos (derecha). Las dos primeras imágenes fueron publicadas por parte del grupo autor de este trabajo (Peralta y col., 2012; la tercera es de una autora de este trabajo (Pérez, 2013).

Aunque parezca ciencia ficción, recientes investigaciones científicas argentinas indican que, con algunas variantes, este relato podría ser adaptado a los seres humanos y protagonizado por una planta de las sierras argentinas cuyo nombre científico es Dalea elegans. Se trata de una leguminosa (al igual que la soja) productora de un compuesto identificado originalmente con el nombre químico de2',4'-dihidroxi-5'-(1'",1"'dimetilalil)-6-prenilpinocembrina y abreviado como 6PP (Caffaratti et al., 1994).

Este flavonoide tiene dos efectos sobre cepas del hongo Candida albicans resistente a medicamentos denominados azoles. El primero es antimicótico per se y el segundo es inhibitorio de los transportadores $\mathrm{ABC}$ cdr con la consiguiente reversión de resistencia (Peralta et al., 2012; Pérez et al, 2003).

Candida albicans es un hongo oportunista que convive naturalmente con otros microorganismos en distintos tejidos de nuestro cuerpo sin causar daño. Sin embargo, en determinadas circunstancias puede provocar infecciones que se manifiestan en la piel (manchas, pie de atleta), uñas, vagina, etc. Sus lesiones están extensamente difundidas en pacientes inmunodeprimidos como consecuencia de malnutrición, transplantes, SIDA, etc. Estos conceptos tienen larga data en el ámbito científico y han sido comunicados en múltiples medios académicos y periodísticos por distintas investigaciones como la de Kim y Sudbery (2011) en una revisión. 


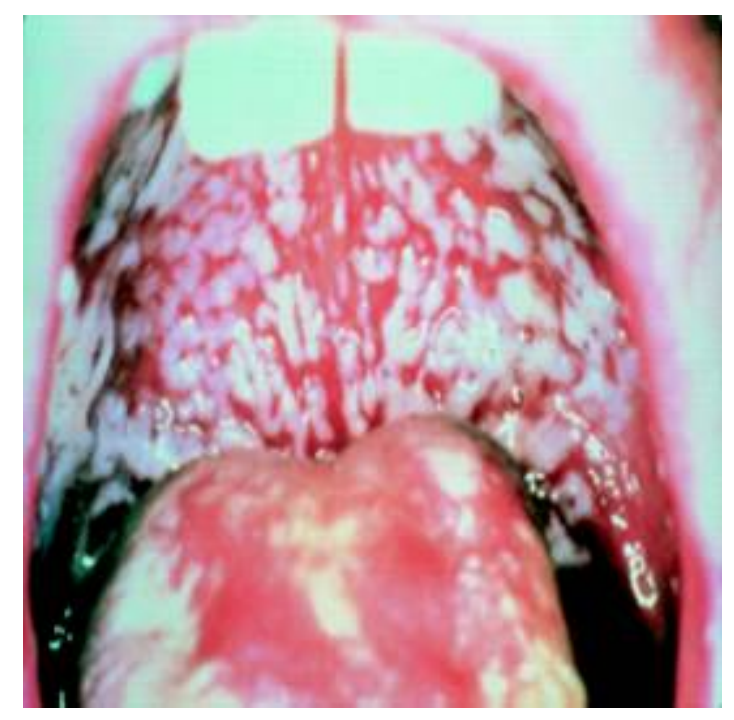

FIGURA 2

Lesiones producidas por Candida albicans en la boca. La fotografía fue cedida cordialmente por el Dr. Sergio Verdú, profesor de Estomatología de la Facultad de Odontología de la Universidad de Buenos Aires.

Quienes padecen de SIDA por ejemplo, suelen presentarlas frecuentemente en boca y faringe, como muestra la Figura 2.

El tratamiento de las candidiasis se realiza con medicamentos denominados antimicóticos. Entre ellos, se utilizan los de tipo azol, como el fluconazol o el miconazol, cuyo uso extensivo incrementó la resistencia a estos, mediada en gran parte por bombas expulsoras. Dado que los azoles son valiosos en terapéutica, convendría seguir utilizándolos, para lo cual sería necesario recuperar su eficacia. Así, es crucial la búsqueda de nuevos medicamentos y estrategias enmarcadas en esta temática (Chambers, 2011).

En este contexto, el 6PPes un potencial medicamento que responde a la estrategia de bloquear in vitro los transportadores ABC cdr (del inglés ATP binding cassette), con lo cual el fluconazol es retenido en la levadura y recupera su eficacia. Por lo tanto, la combinación del 6PP con fluconazol sería más eficaz contra Candida que cada compuesto por separado (Peralta et al., 2012).

Los transportadores citados utilizan la energía liberada por el adenosintrifosfato (ATP), principal acumulador de energía química de los seres humanos. El $95 \%$ de dicho compuesto es producido en las mitocondrias, que son las usinas celulares más importantes. El 6PP compite con el fluconazol en su sitio de reconocimiento y con el ATP en el sitio generador de energía (Barceló et al. 2014, ver Figura 7).

El 6PP es una sustancia de color amarillento, clasificada como flavonoide y aislada a través de distintas técnicas cromatográficas. Tiene una fórmula muy poco frecuente en la naturaleza y fue identificada por primera vez en la Universidad Nacional de Córdoba por Caffaratti et al. (1994, ver Figura 1).

Los flavonoides están ampliamente distribuidos en el reino vegetal y cumplen distintas funciones en el crecimiento y desarrollo. Por ejemplo, algunos atraen abejas y colaboran en la dispersión de semillas y la polinización. Se conoce muy poco sobre las funciones del 6PP.

En cambio, y particularmente en los niveles educativos primario y secundario son más conocidas otras sustancias de origen vegetal, como la clorofila, que interviene en procesos de fotosíntesis que producen moléculas alimenticias aprovechando la luz, el dióxido de carbono y agua del ambiente.

Para la selección y adecuación de conocimientos a difundir se tomó como referencia central un artículo de divulgación (Pérez 2013). 


\section{OBJetivos}

- Acercar e integrar conocimientos sobre el cuidado de la salud, las infecciones, su prevención y tratamiento.

- Divulgar hallazgos científicos de la UBA acerca del potencial medicamentoso de algunos recursos vegetales.

- Enseñar procedimientos de laboratorio utilizados en la docencia e investigación científica.

- Incentivar el interés del alumnado por la investigación científica, sus fundamentos y aplicaciones en la vida cotidiana.

\section{Conocimientos PREvios}

Biología. Clasificación, características y organización celular de los seres vivos. Membrana plasmática, composición química y funciones. Mecanismos de pasaje a través de esta; transporte activo y pasivo. Generación de energía celular. Microorganismos; características y clasificación. Microscopía.

Química. Tipos de uniones químicas. Compuestos orgánicos. Biomoléculas: proteínas estructuras primaria, secundaria, terciaria y cuaternaria. Enzimas. Transportadores. Sistemas materiales homogéneos y heterogéneos. Métodos de separación de componentes de mezclas: cromatografía

\section{Modo de trabajo}

Se diseñaron clases teóricas y prácticas en forma conjunta con estudiantes de $1^{\circ}, 2^{\circ}$ y $4^{\circ}$ año del Colegio $n^{\circ}$ 5 Monseñor Angelelli (Distrito escolar 15) del Ministerio de Educación de la ciudad de Buenos Aires. Los trabajos se realizaron en el laboratorio y aulas del colegio a razón de 2 horas semanales durante 12 semanas.

Se aprovecharon los conocimientos previos del alumnado relacionados con el tema a tratar y a continuación se difundieron saberes científicos en forma simplificada.

Desde el punto de vista pedagógico, se aplicaron distintos procedimientos de la enseñanza de las ciencias experimentales, como planteamiento de problemas, propuestas de soluciones, selección de métodos de concreción, experimentación, análisis e interpretación de resultados (Grinchpum y Gómez, 2004; Krum de Nicolaus, 1999).

Para introducir al alumnado en el método científico, se fomentó la observación, registro de datos, interpretación, análisis y conclusiones.

Se tomaron los recaudos de bioseguridad a fin de prevenir injurias en el estudiantado. También se impartieron normas de conducta para trabajar en laboratorios de microbiología y química (Jamison Noble, Proctor \& Smith, 1996).

\section{Actividades desarrolladas}

\section{Clases teóricas}

Se realizó una indagación mediante prueba oral dialogada acerca de los conocimientos previos del alumnado, para luego introducirlo en el tema. Al último efecto, se hizo una selección e integración de conocimientos de las asignaturas de biología (I y II, $1^{\circ}$ y $2^{\circ}$ año, respectivamente) y química ( $4^{\circ}$ año). Luego se añadieroncontenidos de microbiología y farmacología, necesarios para entender en un paso subsiguiente algunos datos científicos generados por nuestro equipo de la Universidades de Buenos Aires y el CONICET. 
Siguiendo esquemas de Grinchpum y Gómez (2004), se planteó el tema central como un problema a resolver. Este abarcó infecciones comunes en adolescentes como las producidas por hongos, en particular por Candida albicans. Se desarrollaron distintos aspectos, como su diagnóstico, observación por microscopía, cultivo, desarrollo, tratamiento, etc. Se informó acerca del desarrollo de resistencia a medicamentos, sus mecanismos y la necesidad de investigar sobre estrategias para revertirla; a continuación, se dieron ejemplos de investigaciones recientes, publicadas en medios científicos y periodísticos (Barceló et al., 2014; Peralta et al., 2012; Pérez, 2013).

\section{Trabajos prácticos}

\section{Visualización de levaduras y otras células a través del microscopio óptico. Toma de muestras}

Dado que Candida albicans es riesgosa para la salud, para ilustrar algunas de sus características en forma biosegura se recurrió a una especie inocua que tiene similitudes morfológicas, como la ampliamente conocida levadura de cerveza (Saccharomyces cerevisiae), utilizada en alimentación para elaboración de panes y bebidas.

En un tubo de plástico se prepararon $5 \mathrm{ml}$ de una solución de agua azucarada y se le agregó una punta de espátula de levadura de cerveza (Figura 3). Al cabo de 3 minutos se depositó una gota sobre un portaobjetos y observaron levaduras en gemación a través del microscopio (Figura 4).

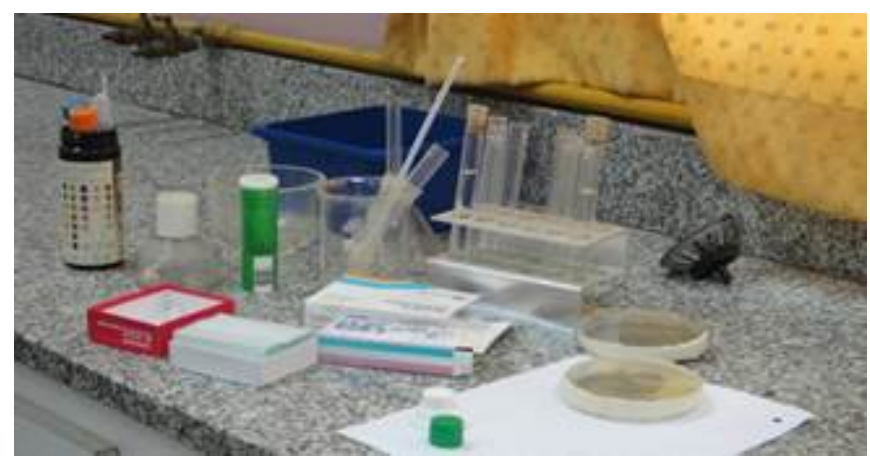

FIGURA 3

Algunos materiales utilizados

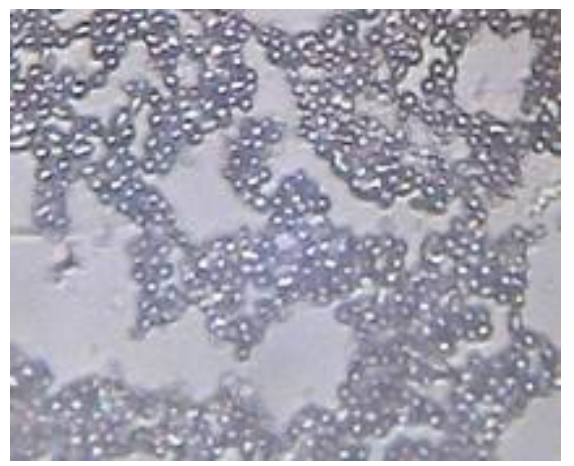

FIGURA 4

Cultivo de levadura de cerveza

Además, se observaron portaobjetos que contenían distintos microorganismos, como Candida albicans y bacterias con forma de cocos (estafilococos y estreptococos) y bacilos, tanto Gram positivos como negativos. Se los dibujó en pizarrones y cuadernos y se los relacionó con su localización en el organismo y las infecciones. 
La observación se realizó con la ayuda de láminas proyectadas a través de medios audiovisuales. Con el objetivo de que los grupos de estudiantes pudieran observar y comparar otros tipos celulares, se realizó la visualización de un preparado previamente teñido de células sanguíneas humanas, algunas de las cuales intervienen en la defensa del organismo ante infectantes (Figura 5).

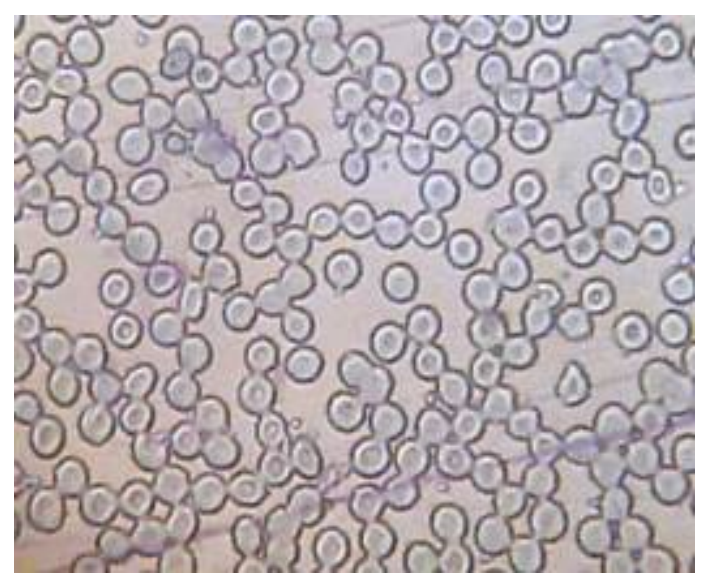

FIGURA 5

Frotis de sangre humana (tinción de May-Grunwald Giemsa), cortesía de la Dra. Cristina Pérez, profesora de la FOUBA.

A continuación, se mostraron células vegetales obtenidas por raspaje de la superficie de hojas de una planta del vecindario; se observó mayor tamaño y estructuras específicas como la pared celular, cloroplastos y estomas.

\section{Mostración de actividad antimicrobiana del 6PP}

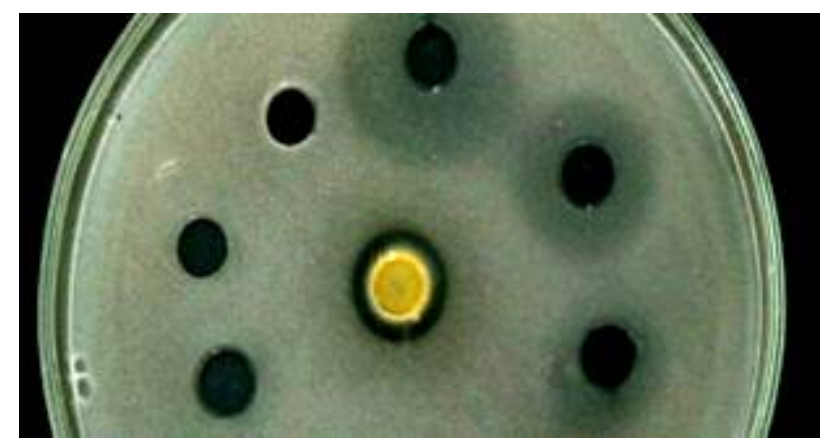

FIGURA 6

Halos de inhibición sobre un cultivo de Candida albicans.

Para ilustrar la actividad antimicótica del 6PP, se explicaron las técnicas utilizadas a través de medios audiovisuales y se mostraron cápsulas de Petri con halos de inhibición producidos por el 6PP sobre el cultivo en agar de Candida albicans (Figura 6). Este material provino de la UBA y fue realizado mediante métodos descritos previamente (Pérez et al., 2003).

\section{Análisis de medicamentos antimicóticos, resistencia y estrategias de resolución}

Dado que el alumnado había traído muestras de medicamentos antimicóticos de sus hogares, se analizaron los prospectos y seleccionó el fluconazol como ejemplo de principio activo. Se explicó cómo este ingresa por 
difusión simple al hongo y ejerce su función antimicrobiana al inhibir proteínas enzimáticas que sintetizan ergosterol, un compuesto fundamental de la membrana plasmática. El uso intensivo de este medicamento puede hacerle perder eficacia, debido a la emergencia de resistencia en Candida albicans. Esta resistencia es mediada en forma importante por transportadores que expulsan el fluconazol hacia el exterior celular, con lo cual ste no puede ejercer su acción en el interior (Figura 7).

Una estrategia farmacológica consiste en bloquear los transportadores, con lo cual se restituye la eficacia del medicamento. Tal efecto puede ser producido por el compuesto 6PP.

El flavonoide se une a los transportadores de tipo cdr, proteínas de forma helicoidal que utilizan al ATP como fuente de energía. Es más, se puedeunir a dos sitios: el de reconocimiento del medicamento a expulsar y el de generación de energía, según trabajos recientes de la UBA (Barceló et al., 2014), como se muestra en la Figura 7 y video.

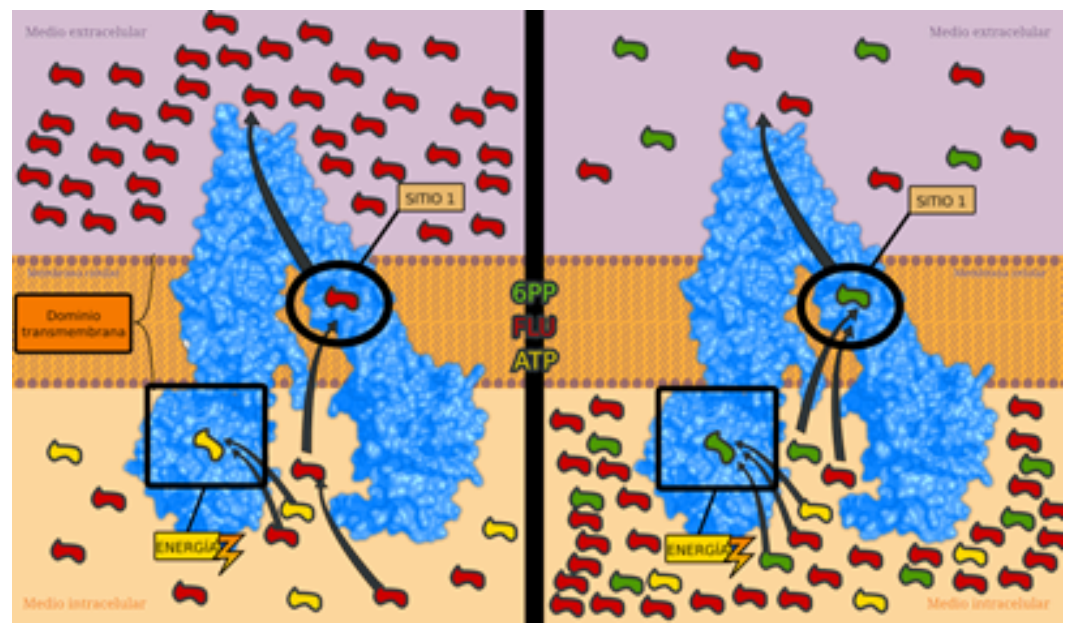

FIGURA 7.

Esquema del transportador cdr2 de Candida albicans (lámina reproducida del artículo de Barceló et al., 2014). Izquierda: levadura resistente debido al eflujo de fluconazol (rojo) activado por el ATP (amarillo). Derecha: reversión de la resistencia por agregado de 6PP (verde), que inhibe el transportador. El sitio 1 reconoce al fluconazol y al 6PP (circunferencia), mientras el generador de energía se enmarca en un cuadrado.

\section{MPEG \\ Video Interacciones.mpg}

VIDEO 1

Interacciones 6PP- transportador. Distintos enlaces químicos involucrados Link:https://drive.google.com/open?id=0B4XtbT4IhWxUa3R0NTJHbThmWHhNd1hqMG5TS2t6cmY0eUZV

\section{Experimento de captación y retención de rodamina}

A fin de ilustrar experimentalmente la reversión de resistencia mostrada en el punto anterior, se realizó una transposición didáctica de algunos resultados científicos de Peralta et al. (2012). 
Se preparó una solución de agua azucarada y se la distribuyó en tres tubos de ensayo numerados del 1 al 3. En otro tubo se depositó, con la punta de una espátula, levadura de cerveza a $5 \mathrm{ml}$ de agua, se mezcló y agregó $1 \mathrm{ml}$ de la suspensión resultante a cada tubo numerado (Figura 3).

En los tubos 2 y 3 se agregó una solución acuosa previamente preparada de rodamina 6G, un colorante fluorescente que es captado por las levaduras por difusión simple y permite en este caso simular el contenido del medicamento antimicrobiano fluconazol. Al cabo de 20 minutos, se separó el sobrenadante fucsia del tubo 3 incubado con rodamina y se lo reemplazó por la solución azucarada. Luego de 15 minutos de incubación se colocó una gota de cada suspensión en sendos portaobjetos y observó al microscopio óptico. Las imágenes de la Figura 8 fueron captadas por estudiantes a través del ocular y corresponden a los tubos 2 y 3 . El color rosado más pronunciado con respecto al tubo 3 se debe a la mayor retención de rodamina por las levaduras, debida al menor eflujo al estar en contacto con el colorante. Los tubos 2 y 3 imitan los resultados obtenidos por Peralta et al. (2012) al incubar levaduras con rodamina en presencia y ausencia del 6PP, respectivamente (ver información científica y exposición audiovisual).
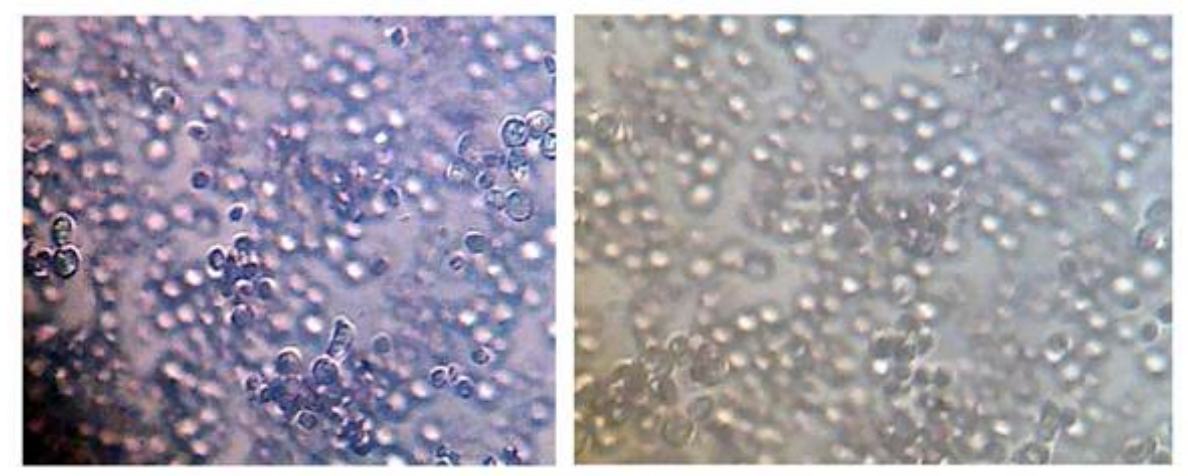

\section{FIGURA 8}

Observación microscópica de células de levadura de cerveza que contienen rodamina $6 \mathrm{G}$ (tubos 2 y 3 , respectivamente).

\section{Extracción y cromatografía de productos de origen vegetal.}

Recordamos de la biología que las células de hojas verdes observadas producen distintas sustancias, como la clorofila, un pigmento verde que interviene en la fotosíntesis. Luego procedimos a extraer dicho compuesto utilizando procedimientos de fragmentación de hojas con tijeras y mortero, seguidos del agregado de alcohol etílico al material vegetal (Figura 9). 


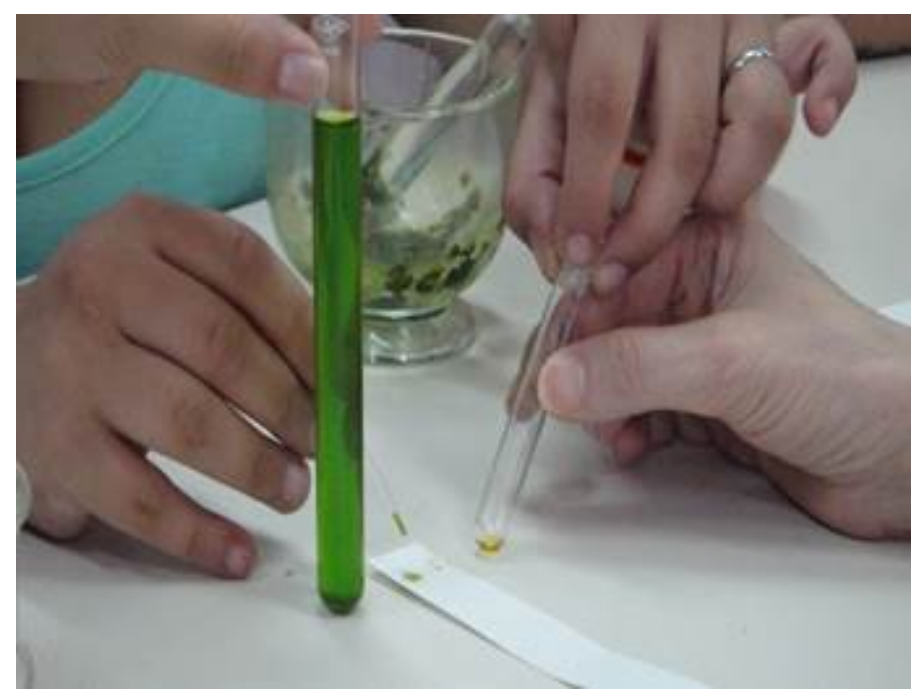

FIGURA 9

Extracción de pigmentos vegetales.

Además de la clorofila, las plantas producen numerosos compuestos, entre ellos el flavonoide 6PP (Figura 1). Relacionando ambos compuestos de origen vegetal, se realizó una cromatografía en papel del extracto de hojas y el 6PP, utilizando como solvente una combinación alcohol etílico/ agua 9/1 v/v (Figura10).
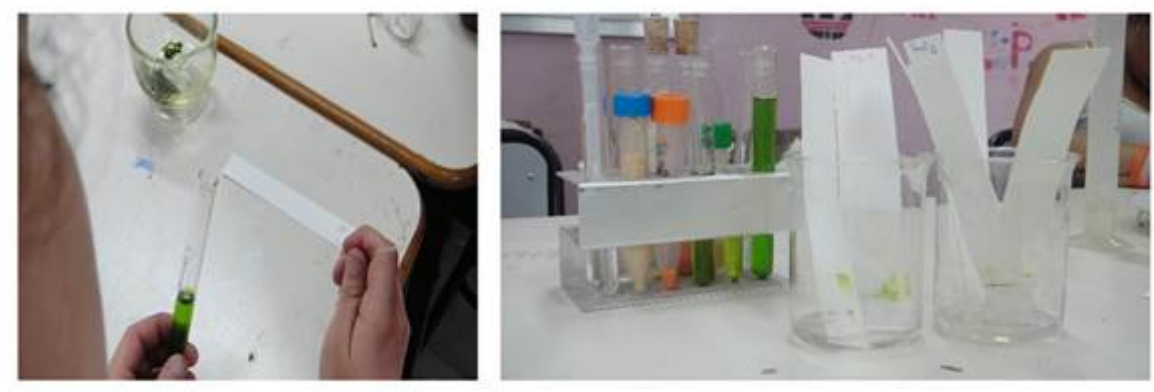

FIGURA 10

Izq.: Extracto alcohólico de hojas de una planta, verde intenso, que contiene

la clorofila entre otros compuestos. Se preparó el papel para cromatografía y se sembró el extracto con un capilar en un punto de la línea y en otro el 6PP. Derecha: cromatograma en curso: el papel está apoyado en un vaso que contiene el solvente.

\section{Evaluaciones y coloquio}

El alumnado rindió examen oral. Se evaluó, a través de un conjunto de preguntas, los conocimientos y criterios científicos adquiridos en función de los objetivos planteados y la enseñanza desarrollada Por otra parte, en un coloquio respondieron preguntas acerca de sus impresiones sobre la experiencia. Así, por ejemplo, comentaron que les había fascinado haber experimentado en "la cocina de la ciencia", lo que significa incursionar en sus métodos teóricos y prácticos, sus inferencias y su aplicación a la vida cotidiana. Todo esto constituiría una novedad en sus vidas, particularmente por haberse relacionado con campos de la medicina. 


\section{Materiales utilizados}

- Material didáctico: pizarrones, láminas, fotografías y videos proyectados a través de medios audiovisuales.

- Material experimental: medios de cultivo de microorganismos, azúcar común (sacarosa), solución fisiológica, reactivos diversos, medicamentos y materiales naturales provenientes de plantas.

- Material fungible: se utilizó, en la medida de lo posible, material de plástico, como tubos, pipetas, gradillas, vasos de precipitado, cápsulas de Petri, morteros, papel secante, capilares, lápices, marcadores, etc.

- Equipamiento: microscopio óptico, computadoras, proyectores de láminas y videos, mecheros, agitadores mecánicos, etc.

- Instalaciones: laboratorios y aulas de la Escuela Monseñor Angelelli de la ciudad de Buenos Aires (GCBA).

- Microorganismos: hongos (levadura de cerveza) y preparados sobre portaobjetos de Candida albicans, así como de bacterias; todo proporcionado en forma biosegura por la Facultad de Odontología o el Hospital de Clínicas dependientes de la UBA.

\section{Resultados y conclusiones. Aportes pedagógicos}

En este trabajo se da cuenta de una actividad docente innovadora de educación científica en una escuela secundaria argentina. Siguiendo premisas de Libedinsky (2001), se relata y describe la experiencia, a fin de socializarla y fomentar su utilización por otrosdocentes. Transposición didáctica mediante el alumnado que participó activamente en la construcción de conocimiento por asociación de contenidos provenientes de sus materias, de disciplinas universitarias y de hallazgos científicos locales.

El currículo escolar se enriqueció, por ende, en relación con disciplinas afines a la medicina y la bioquímica. Más aún, surgió una innovación en la enseñanza de la biología y la química, con apertura novedosa a la investigación científica, sus procesos mentales y experimentales. El estudiantado tuvo la oportunidad de acceder y experimentar con ejemplos de ciencia real, que se diferencia de la escolar en sus objetivos y enfoques.

$\mathrm{Al}$ respecto, se promovió la formación de hábitos y criterios, los cuales conforman pilares esenciales de la educación al generar una apertura mental basada sobre la observación, el razonamiento, la rigurosidad y la proyección a distintos ámbitos (Giordan y Sanmartino, 2004).

Las notas de examen (entre 6 y 10) fueron más altas que las habituales en las materias involucradas. Además, algunos alumnos redactaron, informes minuciosos sobre las actividades desarrolladas. Según lo demostraron y consignaron en coloquios, recibieron esta propuesta con entusiasmo, en particular por la aplicación de lo estudiado al cuidado de su salud y el aprendizaje de algunos procedimientos utilizados comúnmente en laboratorios bioquímicos.

Como era esperable, una vez vencida la reticencia propia de los (adolescentes, la comunicación resultó más directa que con estudiantes de primaria, según nuestra experiencia previa (Pérez, Pagnotta y Rulli, 2003, “Pérez, Pagnini, y Rulli, 2005; Pérez, Flores, Pagnotta, y Rulli, 2013), ya que los alumnos del secundario tienen mayor capacidad de comprensión y abstracción. Fue interesante, además, el intercambio de ideas entre estudiantes, quienes proyectaron sus intereses y vivencias acorde con sus edades.

Desde el punto de vista de las universidades, la propuesta queda enmarcada como extensión de su labor hacia la sociedad, en este caso escuelas secundarias. El contacto fluido entre universidades y escuelas, habitual en países europeos, es fomentado desde hace décadas en la Argentina (Ministerio de Cultura y Educación de la Nación, 1997; Rietti, 1999). Al respecto, en varias cátedras y provincias se han desarrollado trabajos científicos con estudiantes de colegios secundarios. 
El Ministerio de Educación de la Provincia de Córdoba (Argentina) promueve la interacción de investigadores de universidades con docentes de enseñanza media a través de distintas actividades de laboratorio. Otras universidades nacionales organizan ferias, donde divulgan fenómenos y avances científicos.

Desde el punto de vista sanitario, las actividades promovieron el cuidado de la salud, incentivado por la OMS, al propagar valores individuales y sociales a través de la comunidad educativa. En efecto, se enfatizó en brindar conocimientos sobre infecciones comunes en adolescentes, su prevención, tratamiento, problemáticas emergentes y estrategias para resolverlas.

\section{Agradecimientos.}

A las autoridades de la Escuela "Monseñor Angelelli, profesores Patricia Peña y Bernardo Politi, por permitir y alentar estas actividades.

\section{ReFERENCIAS}

Barceló, S., Peralta, M., Ortega, M. G., Cabrera, J. L. y Pérez, C. (2014). Interacciones moleculares de un flavonoide prenilado con transportadores de antimicóticos dependientes de ATP. S. Rev. Fac. de Odon (UBA) 29(66), 26-36.

Caffaratti, M., Ortega, M.G., Scarafia, M. E., Ariza Espinar, L. y Juliani, H. (1994). Prenylated flavanones from Dalea elegans. Phytochemistry 36, 1083-1084.

Chambers, H. F. (2011). Antimicrobials. En Goodman and Gilman (Eds.), The pharmacological basis of therapeutics (pp. 1161-1188). New York: McGraw-Hill.

Díaz, N. y Jiménez, M. R. (2012). Las controversias sociocientíficas: temáticas e importancia para la educación. Revista eureka sobre enseñanza y divulgación de las ciencias 9(1). Recuperado de www.apice-dce.com/actas/ docs/comunicaciones/orales/pdf/084.5-Diaz-Moreno.pdf

Giordan, A., Sanmartino, M. (2004). Educación científica y tecnológica: ¿ por qué y para qué? Novedades educativas, $163,30-32$.

Grinchpum, M. y Gómez, M. (2004). Las experiencias como problemas. Recursos y proyectos. Ediciones Novedades Educativas 163, 39.

Jaim Etcheverry, G. (2001). La tragedia educativa, Buenos Aires, FCE.

Jamison, R., M. A.; Noble, E. M. Proctor, \& J. A. Smith (1996). Laboratory safety in Clinical Microbiology. Cumulative techniques and procedures in Clinical Microbiology. Washington, D. C.: American Society for Microbiology,

Kim, J, Sudbery, P. (2011). Candida albicans, a major human fungal pathogen. J. Microbiol. 49, 171-177.

Krumm de Nikolaus, S. (1999). Los procedimientos en las ciencias naturales. Educación inicial. La Obra, 13(125), 57- 59.

libedinsky, M. (2001). La innovación didáctica emergente. En La innovación en la enseñanza. Diseño y documentación de experiencias de aula (pp.59-73). Buenos Aires: Editorial Paidós.

Ministerio de Cultura y Educación de la Nación. (1997). República Argentina. La ciencia va a la escuela. Zona Educativa, 2(10), 43.

Peralta, M. A., Calise, M., Fornari, C., Ortega, M. G., Diez R. A., Cabrera J. L., C. Pérez C. (2012). A prenylated flavanone from Dalea elegans inhibits rhodamine 6G efflux and reverses fluconazole resistance in Candida albicans. Planta Medica 78(10), 981-987.

Pérez, C., Tiraboschi, I. N., Ortega, M. G., Agnese, A. M.,Cabrera, J. L. (2003). Further antimicrobial studies on 2 ' 4' - dihydroxy- 5'-(1'"' -dimethylallyl)- 6- prenylpinocembrin from Dalea elegans. Pharmaceutical Biology, 41(3), 171-175. 
Pérez, C. (2013). La emulación de estrategias de las plantas permitiría luchar contra microorganismos resistentes que infectan a los humanos. P. ARGENPRESS.info Recuperado de http://www.argenpress.info/2013/04/laemulacion-de-estrategias-de-las.html

Pérez C., Pagnotta, A. M. y Rulli, F. (2003). Novedades científicas en el aula. Novedades Educativas, 151, 8-10.

Pérez, C., Pagnini, A. M. y Rulli, F. (2005). Extensión universitaria: Socialización de conocimientos científicos en una escuela de alto riesgo pedagógico. Aplicaciones farmacológicas de las cáscaras de naranja. Revista Iberoamericana de Educación. (OEI, Barcelona- Bogotá), Recuperado de http://www.campus-oei.org/revista/ experiencias99.htm.

Pérez, C, Flores, T., Pagnotta, A. M. y Rulli, F. (2013). Oxidaciones en biología y farmacología. Integración de conocimientos sobre inmunidad, dieta y medicamentos. Revista sobre Enseñanza y Divulgación de las Ciencia 10(2), 210-218. Recuperado de http://hdl.handle.net/10498/10202http://reuredc.uca.es/. Universidad de Cádiz. España. APAC-Eureka.

Pérez, C., Rodríguez, D. y Rulli, F. (Agosto, 2009). Innovación docente. Infecciones infantiles provocadas por Escherichia coli: síndrome urémico hemolítico y otras. Revista Iberoamericana de Educación, 50(2), 1-9. Recuperado de http://www.rieoei.org/expe/2838Perez.pdf

Rietti, S. (1999). Políticas de ciencia, tecnología y educación para la democratización del conocimiento. La perspectiva desde una política para la ciencia y el desarrollo educativo. Jornadas "Ciencia para todos". Educación permanente: ciencia y tecnología para todos. Buenos Aires, Argentina.

UNESCO-CIUC. (1999). Declaración sobre la ciencia y el uso del saber científico. Recuperado de http:// www.unesco.org/science/wcs/esp/declaracion_s.htm

UNESCO. (2017). Ciencia, tecnología e innovación para el desarrollo sostenible. Recuperado de http:// www.unesco.org/new/es/office-in-montevideo/ciencias-naturales/ciencia-tecnologia-e-innovacion/

\section{BY-NC-ND}

